\title{
Particle Packing Application for Improvement in the Properties of Compressed Stabilized Earth Blocks with Reduced Clay and Silt
}

\author{
S. N. Malkanthi \\ Department of Civil Engineering \\ University of Ruhuna \\ Sri Lanka \\ snmalkanthi@cee.ruh.ac.lk
}

\author{
A. A. D. A. J. Perera \\ Department of Civil Engineering \\ University of Moratuwa \\ Sri Lanka \\ asoka@uom.lk
}

\begin{abstract}
Soil as a building material has been used in different forms such as mud, adobe, rammed earth and bricks. The present study focuses on producing Compressed Stabilized Earth Blocks (CSEBs) giving attention to the particle size distribution in the soil mixture. The literature established that compressive strength significantly depends on clay and silt content and $25 \%$ of clay and silt produce optimum results while no attention has been given to the amount of other, larger particles. Soil grading refers to the combination of different-size particles in a soil mixture. The correct selection of sizes in the correct proportion may cause improvements in CSEB properties. This paper explains the application of particle packing technology for the improvement of CSEB properties. The theoretical concepts provide a continuous particle size distribution, and the soil used for the experiments also has a continuous particle size distribution. The soil used in the experiments was subjected to washing to reduce the clay and silt content. Separated clay and silt and large particles of different sizes were added to the mixture to match particle size distribution to the optimization curves as explained in particle packing theories. The experimental results show that the CSEB properties can be significantly improved by modifying particle size distribution to fit the suggested optimization curves. According to the results, the compressive strength improved by more than $50 \%$ with different amounts of cement stabilization. Significant improvements in the dry densities and water absorption ratios of blocks were observed with this particle size modification.
\end{abstract}

Keywords-cement stabilized earth blocks; soil washing; particle packing; optimization curves; compressive strength

\section{INTRODUCTION}

Earthen materials are been used in civil engineering construction worldwide with different forms, such as mud, adobe, rammed earth and bricks. CSEBs are earthen materials made of soil that are stabilized with different additives, such as cement, fly ash, and lime. CSEBs have been investigated as a building material for their advantageous properties. Compressed earth blocks represent a cost-effective and environmentally friendly alternative building material to traditional masonry elements [1]. In practice, CSEBs are made of earth stabilized with up to $10 \%$ cement and pressed either using a hand-operated press or a hydraulically operated, machine-driven press [2]. CSEBs are available as bricks, blocks, interlocking blocks and hollow blocks. Earthen constructions have many advantages, such as thermal comfort, local employment creation and minimal impact on the environment [3]. The use of earthen constructions is not limited to developing countries, even in developed countries, such as Australia, approximately $20 \%$ of the new building market is occupied with earth-based construction projects [4]. Clay and silt content, cement percentage, and soil grading used for CSEB production influence the properties of CSEB [5]. Soil grading refers to a combination of different size particles in a soil mixture. The selection of the correct sizes in the correct proportion may improve CSEB properties. Correct sizes and proportion can be better explained with the theory of particle packing. With this background, the aim of this paper is to explain the application of particle packing technology for the improvement of CSEB properties. To achieve this aim, the following objectives were considered:

- The properties of CSEBs made with different soils and different particle size distributions were tested.

- The soil grade was modified to fit the optimization curve for CSEB production, and the improvements in block properties with different amounts of cement stabilization were assessed.

\section{LITERATURE REVIEW}

A compressed earth block (CEB), also known as a pressed earth block or a compressed soil block, is a building material made primarily from soil compressed at high pressure to form blocks. A mechanical press is used to form blocks out of an appropriate mix of fairly dry inorganic subsoil, non-expansive clay and aggregates. If the blocks are stabilized with a chemical binder such as Portland cement, they are called CSEBs [6]. There are different methods of producing building walls using soil, such as with CSEBs, wattle and daub materials, rammed earth walls, and cob, or in the recent past, mud blocks [7]. Compared to major masonry units such as burnt bricks and cement blocks, CSEBs have considerable advantages related to 
environmental effects. Author in [8] mentions low energy consumption and the use of recyclable material. Authors in [3] explained the advantages of using CSEB in developing countries, as the bricks do not need plastering because they have a finish that is the same as that for wire-cut bricks, hence significantly saving in cost. The major challenges with CSEB have been researched by many studies considering strength and durability. The amounts of clay and silt are the main factors that act both positively and negatively with the properties of CSEBs.

\section{A. Strength of CSEBS}

Compressive strength has become a fundamental and universally accepted unit of measurement to specify the quality of masonry units. Authors in [9] showed the relationship between the clay and silt content and the compressive strength for different soil-cement ratios. In the test results of [9], the compressive strength displayed an increasing tendency with decreasing clay content and, as expected, it was high for high cement contents. However, other researchers used a minimum clay content limited to $15 \%[2,10]$. Based on their experiments, the compressive strength has tendency to increase with decreasing fines content for different amounts of cement. Author in [9] concluded that high compressive strength can be achieved when the plasticity index is low and with $10 \%$ cement. However, he tested blocks made with soil having a minimum clay content of $15 \%$. It was also shown in [5], that a compressive strength of more than $10 \mathrm{~N} / \mathrm{mm}^{2}$ can be achieved, even with a low plasticity index, when the clay content is between $10 \%$ and $15 \%$. The mechanical properties of soil blocks with fiber reinforcement for two different soil types have been investigated in [11]. Both soils had more than $40 \%$ clay and silt content. For these soil types, the maximum compressive achievement was limited to $3 \mathrm{~N} / \mathrm{mm}^{2}$, even with fiber reinforcement. Authors in [12] reported compressive strengths of $1.2,1.9$ and $2.4 \mathrm{~N} / \mathrm{mm}^{2}$ with $5 \%, 8 \%$ and $10 \%$ cement, respectively, when the soil plasticity index is 13.4. Authors in [13] reported compressive strength results of 2.8 and $1.2 \mathrm{~N} / \mathrm{mm}^{2}$ for CSEBs with $7.5 \%$ cement and soil having a plasticity index of 12.6 and 14.4 respectively. However, they did not consider any durability issues. In general, CSEBs with a minimum clay content of $15 \%$ have been tested in many studies, but the amount of larger particles has not been considered, which is the main focus of this paper.

\section{B. Application of Particle Packing Technology for CSEBS}

Soil properties are the dominant factor of CSEBs' properties. Different researcher groups found different soil particle combinations, ingredients, etc. Particle packing technology is an important aspect of concrete technology to select appropriate sizes and shapes of aggregates. The purpose of this section is to review particle packing technology, its application in different areas, and to match it to CSEBs. Particle packing technology considers optimizing the right sizes and amounts of various particles to increase particle density [14]. Additionally, the packing of aggregates for concrete is the degree of how well the solid particles of the aggregates are packed in terms of packing density [15]. The packing density is defined as the ratio of the solid volume of the aggregate particles to the bulk occupied volume. At first, large particles fill the container with large voids and smaller particles are added to reduce the voids. Then, tiny particles are filled to further reduce voids and increase density [16]. When well-graded soil is used for CSEBs, it increases the strength property of the soil blocks. Smaller particles should be selected to fill the voids between large particles to increase packing density. The concept of particle packing optimization has been used in the field of concrete technology, such as highperformance concrete [17] and interlocking paving block development [18]. Authors in [17, 18] focused on an ideal grading curve that represents the grading with the greatest density. These ideal curves help to perform mixture proportion optimization since it is easy to modify the total particle size distribution by adjusting the ingredient proportions. Most studies on particle packing use one of the following particle optimization methods:

- Optimization curves: Groups of particles with a specific particle size distribution are combined in a way that the total particle size distribution of the mixture is closest to an optimum curve. The following are such optimization curves $[14,19]$ :

$$
P(d)=\left(\frac{d}{d_{\max }}\right)^{q}
$$

where $P(d)=$ size cumulative distribution function, $d=$ considered particle diameter $(\mathrm{m}), d_{\max }=$ maximum particle diameter in the mixture $(\mathrm{m}), q=$ parameter $(0.33-0.5)$ which adjusts the curve for fineness or coarseness.

Authors in [19] utilized (1) with $q=0.5$ and as per [14]. Others have suggested values of $q$ in the range of $0.33-0.5$. Equation (1) was modified with the adjustment factor $q=0.37$ for optimum packing [20]:

$$
P(d)=\frac{d^{q}-d_{\min }^{q}}{d_{\max }^{q}-d_{\min }^{q}}
$$

Author in [21] proposed a maximum density line that provides a guide to blend aggregates and obtain maximum density [21]. Authors in [14] showed that when the packing density is high, high compressive strength can be achieved.

- Particle packing models: These models are analytical models that calculate the overall packing density of a mixture based on the geometry of the combined particle groups. These models are discrete, hence, they consider the definite sizes of different particles.

- Discrete element models: These models simulate the virtual particle structure from a given size distribution.

Considering the nature of the above-mentioned three optimization methods, an optimization curve is used to compare the soils used in this study.

\section{RESEARCH METHODOLOGY}

As the main consideration of this paper, focus was given on particle packing concepts. First, different soil types were checked for clay and silt content. Specifically, a wet sieve analysis test was performed in accordance with ASTM 117 [22] to determine the clay and silt percentage of the tested soil 
samples. CSEBs were cast from all the tested soil types. Based on the research scope, one soil type was selected. The selected soil was washed in order to reduce clay and silt content. In this study, washed soil contained 5\% clay and silt. This washed soil was used to produce CSEBs, and its grading was modified to match the particle packing concept by adding large-size particles that were separated from the same soil earlier. Then, previously separated clay and silt (fines) were added to create fine particle percentages of $5 \%, 7.5 \%$ and $10 \%$. For each fines content, $4 \%, 6 \%, 8 \%$ and $10 \%$ cement content was used as stabilizer. For each combination, 10 blocks were cast, resulting in a total of 120 blocks. Blocks of $150 \mathrm{~mm} \times 150 \mathrm{~mm} \times 150 \mathrm{~mm}$ were prepared using a commercially available cement sand block-making machine. Both vibration and compaction were applied for block casting. The vibration time was regulated based on the preliminary test conducted. Cast blocks were cured using wet gunny bags and sprinkling water for 7 and 28 days. The cast blocks were tested to determine their dry and wet compressive strengths, dry density and water absorption, as per SLS 1382 (Part 2) [23]. Each soil block was placed carefully in the testing machine below the center of the upper bearing block, and load was added until failure. Using the load at failure, the compressive strength could be determined. Figure 1 shows the testing procedure and cast blocks.

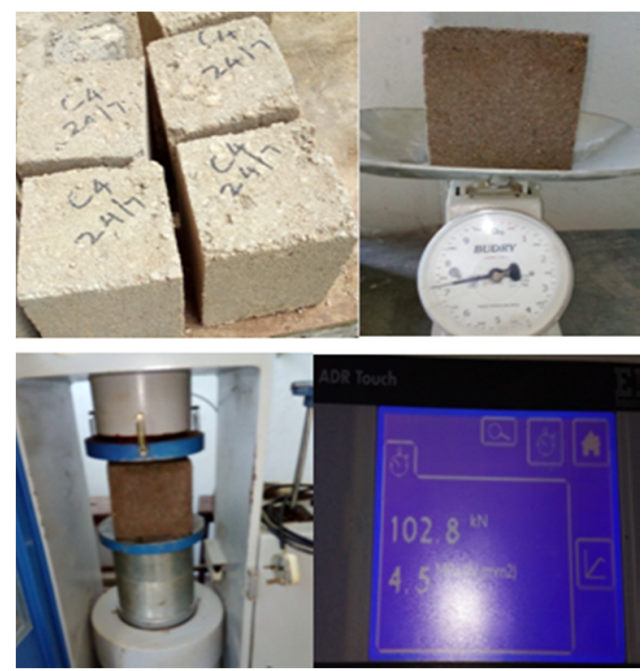

Fig. 1. Cast blocks and compressive test procedure

The dry density of the blocks was determined after keeping the blocks in the oven for more than $24 \mathrm{~h}$ at $105^{\circ} \mathrm{C}$. Each specimen was oven-dried to a constant mass, weighed and measured to determine its dry density.

$$
D_{d}=\frac{\operatorname{Drymass}(\mathrm{Kg})}{\operatorname{Volume}\left(\mathrm{m}^{3}\right)} \times 10^{6}
$$

To determine the water absorption of the blocks, the ovendried test specimens were immersed in water for $24 \mathrm{~h}$ and the increase in the mass of each oven-dried test specimen was calculated and expressed as a percentage of the specimen's initial dry mass.

$$
W=\frac{\text { Saturated surface dry mass }(g)-\text { oven } \operatorname{dry~mass~}(g)}{\text { Oven } \operatorname{dry} \operatorname{mass}(g)} \times 100
$$

\section{TESTING THE PARTICLE PACKING APPLICABILITY}

Initially, five soil types designated as S1, S2, S3, S4 and S5 were selected for preliminary testing. The S1 soil is industrially washed soil. The S3 and S5 soils are naturally available lateritic soils. The S2 and S4 soils were derived by washing of the S3 and S5 soils, respectively, to reduce clay and silt content. Table I denotes the soil grading distribution for each soil. Figure 2 shows a comparison with optimization curves based on the theoretical grading curves explained above. All the theoretical curves were considered within the particle size region of $0.075 \mathrm{~mm}$ to $12 \mathrm{~mm}$.

TABLE I. SOIL GRADING DISTRIBUTION

\begin{tabular}{|c|c|c|c|c|}
\hline \multirow{2}{*}{$\begin{array}{c}\text { Soil } \\
\text { type }\end{array}$} & \multicolumn{4}{|c|}{ Particle size } \\
\cline { 2 - 5 } & $\mathbf{0 - 0 . 0 7 5}$ & $\mathbf{0 . 0 7 5 - 2 . 0}$ & $\mathbf{2 . 0 - 6 . 0}$ & $\mathbf{6 . 0 - 1 2 . 0}$ \\
\hline S1 & 5 & 82 & 9 & 3 \\
\hline S2 & 23 & 24 & 23 & 30 \\
\hline S3 & 35 & 25 & 15 & 25 \\
\hline S4 & 19 & 28 & 20 & 33 \\
\hline S5 & 40 & 30 & 10 & 25 \\
\hline
\end{tabular}

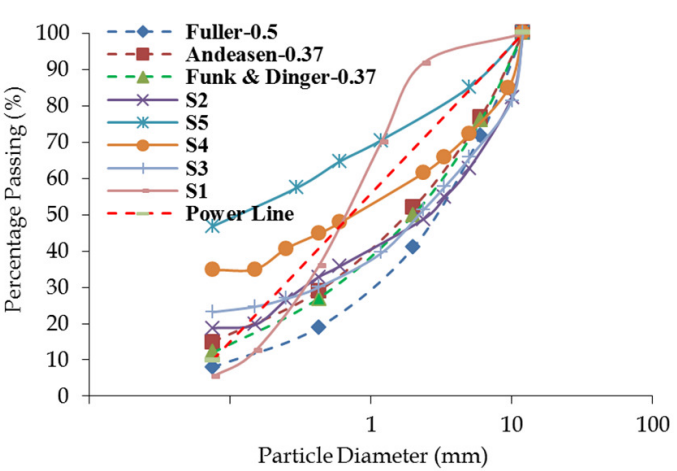

Fig. 2. Comparison of the particle distribution of the used soil with the theoretical distribution

These five types of soil with the same cement content added $(6 \%)$ were used for block casting, and the cast blocks were tested after 28 days for wet and dry compressive strength, block density and water absorption. Considering the presented soil types and optimization curves, the particle size distribution of soil types S2 and S3 are closer to the optimization curves.

\section{A. CSEB Properties vs Optimization Curves}

Five selected soil types were used for CSEB manufacturing. Table II gives the tested properties for cast CSEBs. Among the studied soil types, blocks made with soil types S2 and S3 have comparatively high dry and wet compressive strength. However, the other properties of the blocks do not have the highest values but are within the acceptable range specified by [23-25]. These standards define compressive strength values under three grades and those are Grade 1 (strength value is above 6.0MPa), Grade 2 (4.0-6.0MPa) and Grade 3 (2.84.0MPa). The minimum density is $1750 \mathrm{Kg} / \mathrm{m}^{3}$ and the maximum water absorption is $15 \%$. Blocks made with $\mathrm{S} 1$ soil type have high density but low strength. Therefore, blocks with S1 were tested with different cement contents, and the results are shown in Table III. The S1 soil has 5\% fines after washing of the originally available soil. Figure 3 shows the graphical representation of these results. 
TABLE II. BLOCK PROPERTIES ( $6 \%$ CEMENT)

\begin{tabular}{|c|c|c|c|c|c|}
\hline \multirow{2}{*}{$\begin{array}{l}\text { Soil } \\
\text { type }\end{array}$} & \multirow{2}{*}{$\begin{array}{c}\text { Fines } \\
\%\end{array}$} & \multicolumn{2}{|c|}{$\begin{array}{c}\text { Compressive strength } \\
\text { (MPa) }\end{array}$} & \multirow{2}{*}{$\begin{array}{c}\text { Dry } \\
\text { density } \\
(\mathrm{kg} / \mathrm{m} 3)\end{array}$} & \multirow{2}{*}{$\begin{array}{c}\text { Water } \\
\text { absorption } \\
(\%)\end{array}$} \\
\hline & & 28-day dry & 28-day wet & & \\
\hline S1 & 5 & 1.06 & 0.55 & 1956 & 9.5 \\
\hline S2 & 19 & 3.01 & 1.55 & 1854 & 12.9 \\
\hline S3 & 23 & 2.95 & 0.82 & 1778 & 19 \\
\hline S4 & 33 & 1.98 & 0.69 & 1713 & 18.5 \\
\hline S5 & 40 & 0.99 & 0.25 & 1481 & 31 \\
\hline
\end{tabular}

TABLE III. BLOCK PROPERTIES - VARYING CEMENT CONTENT

\begin{tabular}{|c|c|c|c|c|c|}
\hline \multirow{2}{*}{$\begin{array}{c}\text { Cement } \\
\%\end{array}$} & \multicolumn{2}{|c|}{ Compressive strength (MPa) } & $\begin{array}{c}\text { Dry } \\
\text { Density } \\
\text { (kg/m }\end{array}$ & $\begin{array}{c}\text { Water } \\
\text { Absorption } \\
(\mathbf{\%})\end{array}$ \\
\hline 4 & 0.56 & 0.71 & 0.47 & 1820 & 10.0 \\
\hline 6 & 0.85 & 1.06 & 0.55 & 1956 & 9.5 \\
\hline 8 & 1.95 & 2.26 & 1.27 & 1956 & 10.2 \\
\hline 10 & 3.96 & 4.49 & 3.42 & 1940 & 8.75 \\
\hline
\end{tabular}

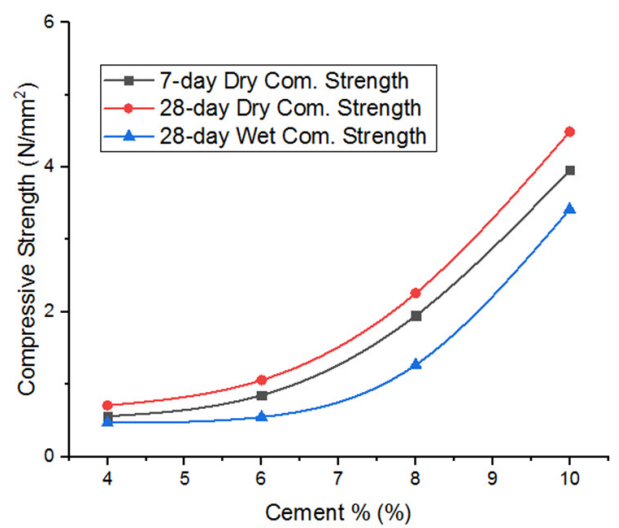

Fig. 3. Compressive strength of soil blocks with $5 \%$ fines, $20 \%$ quarry dust, and S1 Soil

Although the soil gradation does not match the available optimization curves, the strength can still be improved with cement addition. However, many past studies highlighted that more than $10 \%$ cement is not economical. Therefore, this study concerns soil grading near the optimization curve at low cement content. Therefore, the available S1 soil type was modified by adding larger particles to match the power line for CSEB production, and those blocks were tested. The final soil grading is shown in Figure 4 with the corresponding comparison to the optimization curves. This modified soil was used to cast blocks with varying cement content. Additionally, the influence of adding quarry dust was tested with $20 \%$ quarry dust and $0 \%$ quarry dust. Figure 5 shows the 28-day dry compressive strength for blocks made with modified S1 soil and $0 \%$ and $20 \%$ quarry dust for varying cement and fines content. We see that maximum compressive strength for all fines contents can be achieved with $10 \%$ cement content. Also, the use of quarry dust for the mixture does not have a significant influence on strength. The wet compressive strength, dry density and water absorption results for the tested blocks are shown in Table IV. The water absorption ratio clearly shows a notable improvement when optimizing particle packing. The dry density values also show that all the blocks made with upgraded soil arrangements achieve values of more than $1800 \mathrm{~kg} / \mathrm{m}^{2}$. The SLS 1382 minimum value is $1750 \mathrm{~kg} / \mathrm{m}^{2}$.

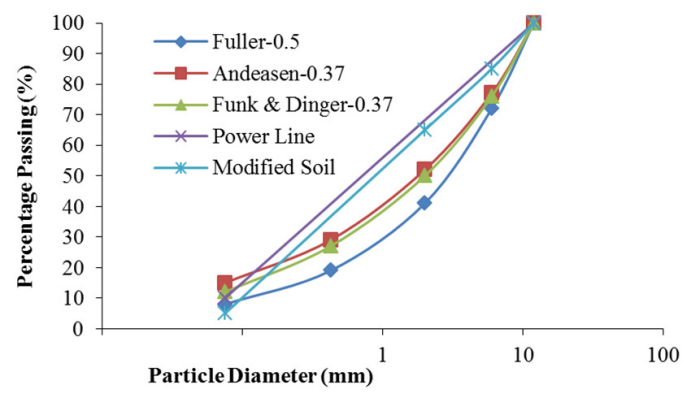

Fig. 4. Particle size distribution of the modified soil

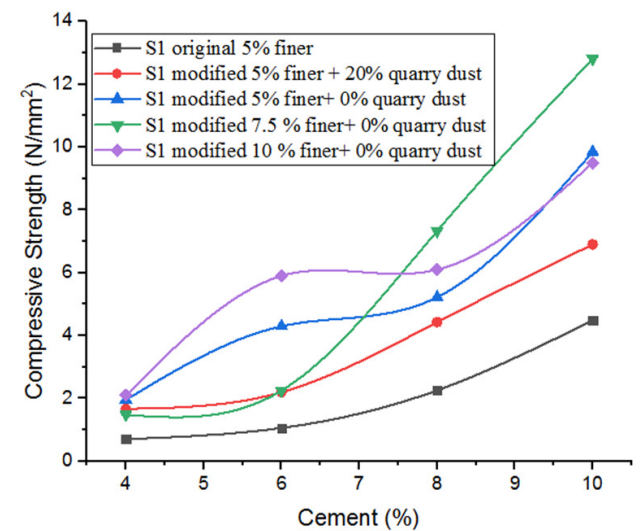

Fig. 5. 28-day compressive strength results of soil blocks with modified soil

TABLE IV. BLOCKS' DRY DENSITY AND WATER ABSORPTION

\begin{tabular}{|c|c|c|c|c|c|}
\hline Soil type & $\begin{array}{c}\text { Clay } \\
\text { and silt } \\
\%\end{array}$ & $\begin{array}{c}\text { Cement } \\
\%\end{array}$ & $\begin{array}{c}\text { 28-day wet } \\
\text { compressive } \\
\text { strength (MPa) }\end{array}$ & $\begin{array}{c}\text { Dry } \\
\text { density } \\
(\mathrm{kg} / \mathrm{m} 3)\end{array}$ & $\begin{array}{c}\text { Water } \\
\text { absorption \% }\end{array}$ \\
\hline \multirow{4}{*}{$\begin{array}{l}\text { S1 washed soil } \\
\text { to obtain } 5 \% \\
\text { fines, } 20 \% \\
\text { quarry dust }\end{array}$} & \multirow{4}{*}{5.0} & 4 & 0.47 & 1820 & 10.0 \\
\hline & & 6 & 0.55 & 1956 & 9.5 \\
\hline & & 8 & 1.27 & 1956 & 10.2 \\
\hline & & 10 & 3.42 & 1940 & 8.75 \\
\hline \multirow{4}{*}{$\begin{array}{l}\mathrm{S} 1 * \text { and } 20 \% \\
\text { quarry dust }\end{array}$} & \multirow{4}{*}{5.0} & 4 & 1.17 & 2009 & 8.43 \\
\hline & & 6 & 1.26 & 2009 & 9.2 \\
\hline & & 8 & 2.75 & 2009 & 7.7 \\
\hline & & 10 & 5.26 & 2023 & 5.1 \\
\hline \multirow{4}{*}{$\begin{array}{l}\mathrm{S} 1 * \text { and } 0 \% \\
\text { quarry dust }\end{array}$} & \multirow{4}{*}{5.0} & 4 & 0.88 & 1911 & 9.3 \\
\hline & & 6 & 2.73 & 2009 & 7.1 \\
\hline & & 8 & 4.54 & 2009 & 7.3 \\
\hline & & 10 & 5.65 & 2018 & 7.1 \\
\hline \multirow{4}{*}{$\mathrm{S} 1 *$} & \multirow{4}{*}{7.5} & 4 & 0.7 & 1890 & 11.3 \\
\hline & & 6 & 1.19 & 1961 & 10.1 \\
\hline & & 8 & 5.11 & 2009 & 7.5 \\
\hline & & 10 & 7.69 & 2055 & 6.8 \\
\hline \multirow{3}{*}{$\mathrm{S} 1 *$} & \multirow{3}{*}{10.0} & 6 & 3.2 & 1917 & 8.7 \\
\hline & & 8 & 3.8 & 1865 & 8.7 \\
\hline & & 10 & 5.9 & 1893 & 8.5 \\
\hline
\end{tabular}

S1*: S1 modified to match the power line by larger particle addition

\section{CONCLUSION}

Compressed stabilized earth blocks (CSEBs) have been considered a key researched masonry unit over the past few decades. Many researchers have concluded that the compressive strength increases with decreasing clay and silt content. However, most researchers focused on the clay and silt content only. Their attempts focused on reducing clay and silt 
content by adding different soil, sand, etc. Further, studies of the influence of other larger particle sizes have not been extensively performed.

This study focused on rearranging the particle distribution of the soil to match the optimization curves while reducing the clay and silt content by soil washing. CSEBs produced with this rearranged soil showed improvements in their block properties. For this study, the soil was rearranged for three different clay and silt contents: $5 \%, 7.5 \%$ and $10 \%$. The results show that high compressive strength can be achieved with $7.5 \%$ clay and silt content and $8 \%$ and $10 \%$ cement contents. Most of the compressive strengths are acceptable for Grade I blocks, as per SLS 1382. The dry density and water absorption ratio were also higher than the specified values in SLS 1382. This study mainly considered the strength characteristics of CSEBs. Many studies have been conducted on the durability of CSEBs with comparatively high clay and silt contents. Nevertheless, improvements are needed to enhance the durability of CSEB walls. Clay and silt content consist the main barrier to achieve the expected durability performance. Therefore, this research will be extended to test the durability issues of CSEBs with low clay and silt contents.

\section{ACKNOWLEDGMENT}

This research did not receive any specific grant from funding agencies in the public, commercial, or not-for-profit sectors. The authors would like to acknowledge the support given by Mr. D.M.N. L Dissanayaka, Technical officer of Structural Testing Laboratory, Mr. H.T.R.M. Thanthirige, Technical officer of Building Materials Laboratory, and Mr. T.P.D.G.I. Yohan, Technical Officer of Structural Dynamics and Health Monitoring Laboratory, University of Moratuwa, Sri Lanka.

\section{REFERENCES}

[1] J. D. Sitton, B. A. Story, "Estimating soil classification via quantitative and qualitative feild testing for use in constructing compressed earth blocks", Procedia Engineering, Vol. 145, pp. 860-867, 2016

[2] K. Heathcote, "Compressive strength of cement stabilized presses earth blocks", Building and Research Information, Vol. 19, No. 2, pp. 101105,1991

[3] C. Jayasinghe, A. Perera, S. West, "The application of hand moulded stabilised earth blocks for rural houses in Sri Lanka", International Earth Building Conference, Sydney, Australia, January 19-21, 2005

[4] M. Segetin, K. Jayaraman, X. Xu, "Harakeke reinforcement of soilcement building materials: Manufacturability and properties", Building and Environment, Vol. 42, No. 8, pp. 3066-3079, 2006

[5] B. V. V. Reddy, M. S. Latha, "Influence of soil grading on the characteristics of cement stabilised soil compacts", Materials and Structures, Vol. 47, No. 10, pp. 1633-1645, 2013

[6] https://en.wikipedia.org/wiki/Compressed_earth_block

[7] C. Udawatta, R. Azoor, R. Halwatura, "Manufacturing framework and cost optimization for building Mud cCncrete Blocks (MCB)", 16th Conference of the Science Council of Asia: Mobilization modern technologies for sustainable development in Asia, Colombo, Sri Lanka, May 30-June 1, 2016

[8] D. J. Haris, "A quantitative approach to the assessment of the environmental impact of building materials", Building and Environment, Vol. 34, No. 6, pp. 751-758, 1999

[9] P. J. Walker, "Strength, durability and shrinkage characteristics of cement stabilised soil blocks", Cement \& Concrete Composites, Vol. 17, No. 4, pp. 301-310, 1995
[10] A. Perera, C. Jayasinghe, "Strength characteristics and structural design methods for compressed stabilized block walls", International Masonry Society, Vol. 16, pp. 34-38, 2003

[11] H. Danso, D. B. Martinson, M. Ali, J. B. Williams, "Physical, mechanical and durability properties of soil building blocks reinforced with natural fibres", Construction and Building Materials, Vol. 101, No. 1, pp. 797-809, 2015

[12] C. M. Chan, L. P. Low, "Development of a strength prediction model for "Green" compressed stabilised earthbricks", Journal of Sustainable Development, Vol. 3, No. 3, pp. 140-150, 2010

[13] B. S. Waziri, Z. A. Lawan, Mustapha, M. A. Mala, "Properties of compressed stabilized earth blocks (CSEB) for low cost housing construction: A preliminary investigation", International Journal of Sustainable Construction Engineering \& Technology, Vol. 4, No. 2, pp. 39-46, 2013

[14] S. Fenis, J. C. Walraven, "Using particle packing technology for sustainable concrete mixture design", Heron, Vol. 57, No. 2, pp. 73-101, 2010

[15] M. N. Mangulkar, S. S. Jamkar, "Review of particle packing theories used for concrete mix proportioning", International Journal of Scintific and Engineering Research, Vol. 4, No. 5, pp. 143-148, 2013

[16] S. V. Kumar, M. Santhanam, "Particle packing theories and their application in concrete mixture proportioning: A review", Indian Concrete Journal, Vol. 77, No. 9, pp. 1324-1331, 2003

[17] V. Wong, K. W. Cha, A. K. H. Kwan, "Applying theories of particle packing and rheology to concrete for sustainable development", Organization, Technology and Management in Construction: An International Journal, Vol. 5, No. 2, pp. 844-852, 2013

[18] H. A. C. K. Hettiarachchi, W. K. Mampearachchi, "Validity of aggregate packing models in mixture design of interlocking concrete block pavers (ICBP)", Road Materials and Pavement Desing, Vol. 20, No. 2, pp. $462-$ 474, 2017

[19] W. B. Fuller, S. E. Thompson, "The laws of proportioning concrete", Asian Journal of Civil Engineering Transport, Vol. 59, No. 2, pp. 67143, 1907

[20] J. E. Funk, D. R. Dinger, Coal Grinding and Particle Size Distribution Studies for Coal-Water Slurries at High Solids Content, Empire State Electric Energy Research Corporation, 1980

[21] T. C. Powers, The Properties of Fresh Concere, Wiley, 1968

[22] ASTM, ASTM C 117 (2009): Standard Test Method for Materials Finer than 75- $\mu \mathrm{m}$ (No. 200) Sieve in Mineral Aggregates by Washing, ASTM, 2009

[23] Sri Lanka Standard Institution, SLS 1382 (2010): Specification For Compressed Stabilized Earth Blocks: Part 2 Test Methods, Sri Lanka Standard Institution, 2010

[24] Sri Lanka Standard Institution, SLS 1382 (2010): Specification For Compressed Stabilized Earth Blocks: Part 1 Requirements, Sri Lanka Standard Institution, 2010

[25] Sri Lanka Standard Institution, SLS 1382 (2010): Specification For Compressed Stabilized Earth Blocks: Part 3 Guildlines on Production, Design and Construction, Sri Lanka Standard Institution, 2010 